\title{
Comparación de tres estrategias de tamizaje para la prevención de la infección perinatal por VIH en Colombia: análisis de decisiones
}

\author{
Marcela Gómez ${ }^{1}$
}

Forma de citar

Gómez M. Comparación de tres estrategias de tamizaje para la prevención de la infección perinatal por VIH en Colombia: análisis de decisiones. Rev Panam Salud Publica. 2008;24(4):256-64.

RESUMEN Objetivo. Comparar mediante un modelo de análisis de decisiones tres estrategias de tamizaje de la infección por el VIH en mujeres embarazadas según su relación costo-efectividad y proponer la más apropiada para el sistema de salud colombiano.

Métodos. Estudio económico basado en el análisis mediante árboles de decisión según tres estrategias de tamizaje de la infección por el VIH en mujeres embarazadas: la voluntaria, la universal y la opcional. Se consideró a todas las mujeres colombianas embarazadas sin diagnóstico de infección por el VIH que se presentaban para el parto. Se emplearon los costos médicos directos desde la realización de la prueba hasta un año después del parto, según el Sistema General de Seguridad Social en Salud. Se compararon las razones costo-efectividad y el ahorro de cada estrategia analizada.

Resultados. Por cada 10000 mujeres, la estrategia universal permitió detectar 5 casos más que la estrategia voluntaria y 7 casos más que la opcional. La estrategia universal generó costos aproximados de US\$17,00 por cada recién nacido positivo, es decir, menos de la mitad que lo calculado para la estrategia voluntaria (US\$38,00) y menor que para la opcional (US\$24,00). Según el análisis bifactorial, la estrategia de tamizaje universal fue menos costosa que la voluntaria y más efectiva que las otras dos estrategias, independientemente de la prevalencia, la tasa de positivos falsos del sistema de diagnóstico empleado y la tasa de aceptación materna para realizarse la prueba de tamizaje.

Conclusiones. La estrategia de tamizaje voluntaria, que se utiliza actualmente en Colombia, es más costosa que la universal a mediano y largo plazos y tiene menor efectividad y capacidad de prevención. Se recomienda a las autoridades nacionales de salud realizar el tamizaje de la infección por el VIH a todas las embarazadas colombianas con pruebas de tercera generación.

Palabras clave Transmisión vertical de enfermedades, VIH, tamizaje masivo, atención perinatal, costos y análisis de costo, Colombia.

Fundación Universitaria de Ciencias de la Salud, División de Investigaciones, Santa Fe de Bogotá, Colombia. Dirigir la correspondencia a Fundación Universitaria de Ciencias de la Salud, División de Investigaciones, Carrera 18 No. 8-95, Santa Fe de Bogotá 11001, Colombia. Correo electrónico: m2gomez@ gmail.com
La epidemia de infección por el virus de la inmunodeficiencia humana (VIH) y el sida ha sufrido una transformación en los últimos años. De una enfermedad mortal, el sida ha pasado a ser una enfermedad cró- nica y la infección por el VIH ha dejado de circunscribirse a poblaciones con comportamientos y actitudes de riesgo para extenderse de forma masiva a otros grupos de la población (1). 
Actualmente, cerca de 40 millones de personas viven con la infección por el VIH en el mundo, de ellas 2,5 millones son menores de 15 años (2). Estas cifras pueden ser mucho mayores, ya que un elevado número de personas desconocen que están enfermas; esto empeora aún más la compleja situación epidemiológica. La infección por el VIH constituye una gran carga social para los Estados, no solo por el alto costo económico que representa para los sistemas de salud, sino también por la pérdida de días de trabajo y las afectaciones familiares que provoca.

Se calcula que para el año 2005 en América Latina y el Caribe habrá aproximadamente 2 millones de personas infectadas y cada año se infectarían cerca de 200000 personas más, con un aceleramiento en la tasa de infección de mujeres y el consiguiente aumento en la transmisión de madre a hijo $(2,3)$.

En 2004 en Colombia se notificaron 45790 personas seropositivas por el VIH o con sida, de ellas, 20000 recibieron el diagnóstico en los últimos 6 años. Sin embargo, por cada caso notificado puede haber ocho sin notificar, por lo que el número total de personas con VIH/sida puede llegar a alrededor de 180000 (3). Según datos del Ministerio de la Protección Social de Colombia, la prevalencia de la infección por el VIH en la población general de 15 a 49 años de edad en 2005 era de 0,7\%, con un pronóstico de 1,5\% para el año 2010 (4).

Según los datos oficiales, en Colombia vivían aproximadamente 22 millones de mujeres en 2005 y se esperaba el nacimiento de aproximadamente 950000 niños. Aunque 87,0\% de las embarazadas reciben atención prenatal con controles realizados por un médico y $82,7 \%$ de los partos son atendidos por médicos, $6 \%$ de las mujeres no recibe aún ningún tipo de cuidado durante el parto. La cobertura del Sistema General de Seguridad Social en Salud llega solamente a cerca de $69 \%$ de la población, por lo que alrededor de $31 \%$ de los colombianos no cuenta con ese seguro de salud $(3,4)$.

El patrón de la infección por VIH según el sexo también ha cambiado en los últimos 10 años, con un aumento en las mujeres jóvenes. Se estima que en 2005 en Colombia había 62000 mujeres y 2400 niños infectados. ${ }^{2}$ La alta vulnerabilidad de las mujeres ante la epidemia de VIH/sida puede deberse a múltiples factores, como el contexto machista en el que crecen, la violencia intrafamiliar, las relaciones sexuales tempranas y la desigualdad social, así como al desplazamiento forzoso que ha afectado a una gran parte de la población y que genera desarraigo, desprotección y marginalidad, y propicia que muchas mujeres se dediquen al trabajo sexual (5).

Según datos del Ministerio de la Protección Social de Colombia, la prevalencia general de la infección por el VIH en mujeres embarazadas colombianas - una población altamente vulnerable a todos los factores sociales mencionados- era de cerca de $0,04 \%$ en 2005. Por su parte, la transmisión vertical del VIH representó $90 \%$ de las infecciones pediátricas y entre 50 y $70 \%$ de ellas ocurrieron durante el parto vaginal (6).

Es importante aclarar que si bien la transmisión vertical es efectiva en 26-40\% de los casos sin tratamiento, puede reducirse a menos de $1 \%$ si se aplican medidas preventivas y el tratamiento oportuno (7). Se sabe que 15-20\% de los niños que nacen infectados y no reciben el tratamiento adecuado desarrollan el sida en el primer año de vida y la mayoría muere antes de cumplir cuatro años $(8,9)$. Una gran parte de los niños que nacen infectados no recibe tratamiento, aunque $29 \%$ de ellos presenta signos y síntomas de la enfermedad. Además, la infección por el VIH/sida es una importante causa de estigma y tiene un alto costo social, especialmente en niños por la discapacidad que provoca.

Por las razones expuestas, los sistemas de salud deben tomar medidas eficaces que eviten que los niños contraigan esta infección. Para ello, un primer paso puede ser identificar a las

\footnotetext{
2 Torres C. Situación actual de la infección VIH/sida en Colombia [presentación en evento]. XXIV Congreso Colombiano de Pediatría; 2005, junio 2-5; Cartagena, Colombia. Santa Fe de Bogotá: Sociedad Colombiana de Pediatría; 2005.
}

mujeres embarazadas seropositivas, lo cual es factible debido a la amplia disponibilidad de pruebas de tamizaje de fácil aplicación y de muy elevadas sensibilidad y especificidad (como los sistemas ELISA de tercera generación) (10).

Para reducir la transmisión vertical a menos de $1 \%$ en los niños nacidos de madres seropositivas no solo es necesario aplicar la terapia antirretroviral durante el embarazo, el parto y el puerperio, además se debe realizar el parto por cesárea y suprimir la lactancia materna $(9,10)$.

Desde mediados de 1999 es obligatorio que las entidades de seguridad social colombianas ofrezcan pruebas de diagnóstico de la infección por el VIH a las mujeres embarazadas afiliadas, con lo que teóricamente debe quedar cubierta la totalidad de la población que posee un seguro de salud. Sin embargo, algunas de esas instituciones todavía no ofrecen estos servicios, no solamente en un intento de reducir los gastos, sino muchas veces por el desconocimiento o la interpretación sesgada de la legislación (11).

Existen varias estrategias para establecer el tamizaje de la infección por el VIH en embarazadas. La primera es la voluntaria, basada en la obligación del sistema de salud de ofrecer la prueba durante el control prenatal, con la asesoría necesaria, y la madre decide si la acepta mediante la firma de un documento de consentimiento informado. Si la prueba se ofrece en condiciones adecuadas, los porcentajes de aceptación pueden ser de hasta 70-83\% (12). Aunque esta es la estrategia establecida en Colombia, se debe tener en cuenta que las empresas prestadoras de servicios de salud han establecido un tiempo promedio de consulta médica especializada de 20 minutos por paciente, el cual puede resultar insuficiente para dar toda la información que se requiere sobre la prueba. En encuestas realizadas, cerca de $70 \%$ de los obstetras que asistieron a las ediciones de 2001 y 2002 del Congreso Nacional Colombiano de Ginecología y Obstetricia reconocieron que no ofrecían la prueba a sus pacientes $(13,14)$. Además, este escenario contempla sola- 
mente a aquellas personas que tienen acceso al sistema de seguridad social. Es curioso observar que esta estrategia no ha representado una gran ventaja para la población diana en comparación con la que no cuenta con seguro de salud.

Una segunda estrategia es la llamada universal, mediante la cual se realiza la prueba de tamizaje para anticuerpos contra el VIH como parte de los exámenes habituales que se aplican a todas las mujeres embarazadas. En esta estrategia, las mujeres no necesitan firmar un documento de consentimiento informado, aunque conservan su derecho de rehusarse a que se practique esta o cualquier otra prueba establecida (como las de toxoplasma, perfil hemático, etc.) mediante una firma en su historia clínica $(12,15)$. Aunque esta estrategia puede ayudar a reducir notablemente la transmisión vertical, la asesoría, especialmente la que se debe realizar después de la prueba, es una parte fundamental del resultado y debe contar con el tiempo y la preparación necesarios. Según diversos autores, el porcentaje de aceptación de la prueba en esta estrategia varía entre $90 \%$ y $98 \%$ $(15,16)$.

La estrategia ideal para cualquier sistema de salud debería ser la voluntaria con una cobertura de $100 \%$ (16). Sin embargo, las dificultades propias del sistema general de salud colombiano han impedido convertir esta estrategia en la más apropiada, especialmente debido a las características de la infección por el VIH y sus implicaciones. La selección de la estrategia adecuada de tamizaje se hace más crítica aún cuando se trata de mujeres embarazadas, ya que abre la posibilidad de prevenir la transmisión madre-hijo y el desarrollo de la enfermedad en el niño si se detecta y trata oportunamente $(17,18)$.

El objetivo del presente trabajo es comparar mediante un modelo de análisis de decisiones tres estrategias de tamizaje de la infección por el VIH en mujeres embarazadas según su relación costo-efectividad y proponer la más apropiada para el sistema de salud colombiano.

\section{MATERIALES Y MÉTODOS}

Se realizó un estudio económico basado en el análisis mediante árboles de decisión de tres estrategias de tamizaje de la infección por el VIH en mujeres embarazadas: la voluntaria, la universal y la opcional (la prueba no se ofrece y solo se realiza por solicitud expresa de la embarazada). Para el análisis del costo en función de la efectividad se emplearon los costos estándares del Sistema General de Seguridad Social en Salud. Se consideró como universo a todas las mujeres colombianas embarazadas sin diagnóstico conocido de infección por el VIH que se presentaban en centros de salud del primer, segundo o tercer niveles de atención en condiciones que permitieran anticipar un parto vaginal próximo. Para efectos del análisis se estudió una población constituida por una cohorte hipotética establecida mediante un modelo de simulación de mujeres embarazadas con las mismas características del universo en un término de un año a partir del parto.

Para la construcción de los árboles de decisión se asumió que todas las mujeres asistieron a una sesión informativa antes del parto; los niveles de carga viral materna y el número de madres que se encontraban en el período de ventana inmunológica para un resultado positivo en la prueba del VIH se distribuyeron uniformemente en las diferentes ramas del árbol de decisión; la invitación a someterse a la prueba del VIH antes del parto no provocó el rechazo de las embarazadas; la aceptación al tratamiento y la adhesión al mismo por parte de las madres con resultado positivo fue igual en cualquiera de las estrategias consideradas; y los riesgos y las complicaciones posteriores al parto se distribuyeron homogéneamente entre las estrategias.

Se utilizaron los costos médicos directos a partir del momento de realización de la prueba diagnóstica a la embarazada hasta un año después del parto, aunque no se tomaron en cuenta los costos relacionados con la atención de las madres positivas después del parto. Se realizó un análisis de sensibi- lidad con una y con dos variables para probar la robustez del modelo frente a posibles cambios en las variables. Se evaluaron los niveles factibles de costos con descuentos de hasta 50\% (límite inferior) y aumentos de hasta tres veces (límite superior, establecido por los laboratorios que comercializan los medicamentos fuera del Plan Obligatorio de Salud) $(19,20)$. Las variables de probabilidad se expresaron en porcientos y sus valores se tomaron de revisiones sistemáticas y bases de datos (Medline y Cochrane Collaboration), guías de práctica clínica, información estadística y guías nacionales (cuadro 1). Las variables relacionadas con los costos se expresan en pesos colombianos (\$) y dólares estadounidenses (US\$) según su equivalencia, ${ }^{3}$ a partir de los valores oficiales vigentes en Colombia en 2005 (cuadro 2).

Las medidas de resultado se determinaron en forma dicotómica: recién nacido positivo al VIH (valor 0 ) o negativo al VIH (valor 1) en cada una de las estrategias, según los resultados de la prueba de reacción en cadena de la polimerasa (RCP). Se asumió que se realizó un seguimiento por lo menos hasta las 12 semanas de vida de todos los recién nacidos de madres positivas que tuvieron un resultado positivo según la prueba de la RCP, según se establece en la Guía Nacional de Atención en VIHSida vigente en Colombia (21).

El ahorro se calculó como la razón incremental del costo en función de la efectividad, según la siguiente ecuación: ahorro $=($ costo de la estrategia $2-$ costo de la estrategia 1) / (efectividad de la estrategia 2 - efectividad de la estrategia 1).

Se elaboraron árboles de decisión clásicos en cuanto al balance, la estructuración de los nodos de azar, la superposición de nodos, la estandarización de probabilidades, las variables y la simetría (figuras 1 y 2) (22). Para la realización del árbol y su análisis se utilizó el paquete estadístico DATA v. 3.5 (23).

\footnotetext{
US $\$ 1,00=\$ 2300,00$ pesos colombianos, según tasa establecida por el banco de la República de Colombia para febrero del 2005 (http://www. businesscol.com/economia/dolar_2005.htm).
} 
CUADRO 1. Descripción de las variables de probabilidad empleadas para elaborar los árboles de decisión

\begin{tabular}{|c|c|c|c|c|}
\hline \multirow[b]{2}{*}{$\begin{array}{l}\text { Código de la } \\
\text { variable }^{\mathrm{a}}\end{array}$} & \multirow[b]{2}{*}{ Descripción } & \multicolumn{3}{|c|}{$\begin{array}{l}\text { Valor empleado para elaborar los } \\
\text { árboles de decisión }\end{array}$} \\
\hline & & $\begin{array}{l}\text { Valor } \\
\text { medio (\%) }\end{array}$ & $\begin{array}{l}\text { Intervalo } \\
(\%)\end{array}$ & Referencia \\
\hline Ofrece prueba & Ofrecimiento de la prueba a la embarazada & 30,0 & $0,0-80,0$ & 11,12 \\
\hline Acepta prueba & Aceptación de la embarazada a la prueba en la estrategia voluntaria & 80,0 & $30,0-100,0$ & 15 \\
\hline Acepta prueba 1 & Aceptación de la embarazada a la prueba en la estrategia universal & 95,0 & $80,0-100,0$ & 16 \\
\hline ELISA (+) & Resultados positivos en madres positivas al VIH (sensibilidad) & 99,8 & $40,0-100$ & 16 \\
\hline ELISA (-) & Resultados negativos en madres negativas al VIH (especificidad) & 99,3 & $90,0-100$ & 16 \\
\hline Acepta tto & Probabilidad de que la madre acepte el tratamiento durante el parto & 90,0 & $60,0-100$ & 17 \\
\hline Recién nacido VIH (+) & Probabilidad de la transmisión vertical sin tratamiento & 26,0 & $20,0-40,0$ & 15 \\
\hline
\end{tabular}

${ }^{a}$ Códigos de las variables de probabilidad para los árboles de decisión presentados en las figuras 1 y 2.

\section{RESULTADOS}

En términos de casos detectados por cada 10000 mujeres, la estrategia universal permitió detectar 5 casos más que la estrategia voluntaria y 7 casos más que la opcional.

Al tomar en consideración también los costos relacionados con la atención de los recién nacidos positivos para VIH durante su primer año de vida, la estrategia universal generó costos aproximados de $\$ 39$ 000,00 (US\$ 17,00) por cada recién nacido positivo, es decir, menos de la mitad que lo calculado para la estrategia voluntaria (\$87 000,00; US\$ 37,00) y menor que para la opcional (\$56 000,00; US\$ 24,00) (cuadro 3). La efectividad de la estrategia de tamizaje universal resultó más favorable, además de menos costosa, que las otras dos, lo que la convierte en la mejor estrategia según este modelo.
La implementación del tamizaje universal representaría un ahorro aproximado por cada embarazada positiva adicional detectada durante el embarazo de \$24 millones (US\$ 10400,00 ) con respecto a la estrategia opcional y de $\$ 96$ millones (US\$ 42000,00 ) con respecto a la voluntaria (cuadro 3 ).

En 2005 se registraron alrededor de 950000 nacimientos en Colombia (4) y la prevalencia de $\mathrm{VIH}$ en mujeres embarazadas ese año fue de $0,04 \%$, por lo

CUADRO 2. Descripción de las variables de costo empleadas para elaborar los árboles de decisión

\begin{tabular}{|c|c|c|c|c|}
\hline \multirow{2}{*}{$\begin{array}{l}\text { Código de la } \\
\text { variable }^{\mathrm{a}}\end{array}$} & \multirow[b]{2}{*}{ Prueba o procedimiento } & \multicolumn{3}{|c|}{$\begin{array}{l}\text { Valores empleados para elaborar los } \\
\text { árboles de decisión }\end{array}$} \\
\hline & & Valor medio ${ }^{\mathrm{b}}$ & Intervalo ${ }^{b}$ & Referencia \\
\hline Costo ELISA & Costo de la prueba serológica tipo ELISA & 16500 & $10000-23000$ & 19,21 \\
\hline Costo WB & Costo de la prueba confirmatoria por western blot & 100000 & $80000-120000$ & 19,21 \\
\hline Costo RCP & Costo de la prueba por la reacción en cadena de la polimerasa & 280000 & $200000-360000$ & 19 \\
\hline Costo tto & Costo del tratamiento de la madre durante el parto & 200000 & $150000-250000$ & 19 \\
\hline $\begin{array}{l}\text { Costo consejería } \\
\text { preparto y posparto }\end{array}$ & Costo del servicio de consejería a la madre & 36000 & $32000-58000$ & 21 \\
\hline Costo rn positivo & $\begin{array}{l}\text { Costo del tratamiento del recién nacido positivo al } \\
\text { VIH durante el primer año de vida }\end{array}$ & 54000000 & $36000 \quad 000-81000000$ & 19,21 \\
\hline
\end{tabular}


FIGURA 1. Árbol de decisión para las tres estrategias de tamizaje analizadas ${ }^{\mathrm{a}}$

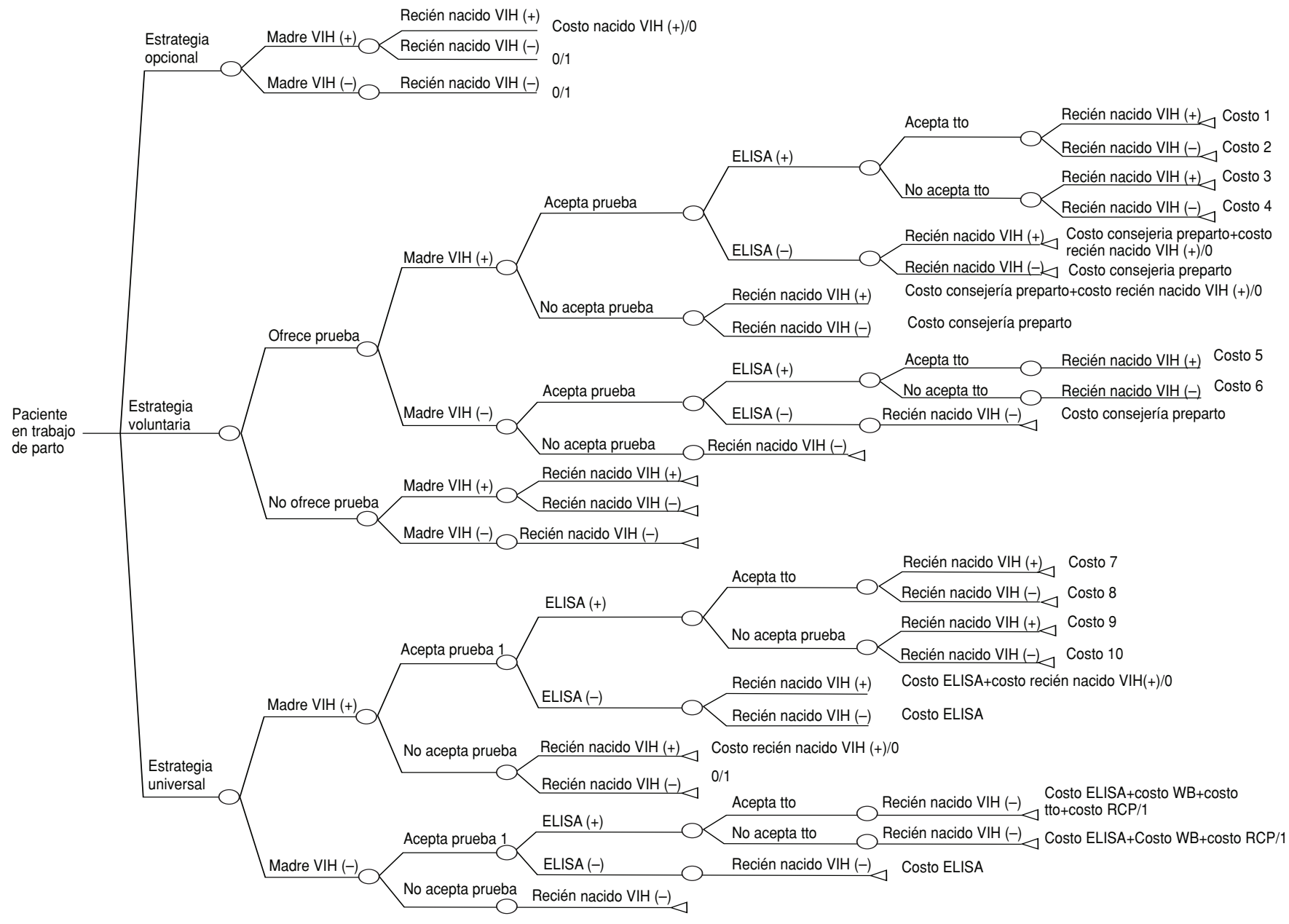

Costo $1=$ (costo de la consejería preparto + costo del ELISA + costo del tratamiento de la madre durante el parto + costo de la consejería posparto + costo del western blot (WB) + costo de la prueba de reacción en cadena de la polimerasa $[\mathrm{RCP}]+$ costo del tratamiento del recién nacido positivo) $/ 0$

Costo 2 = (costo de la consejería preparto + costo del ELISA + costo del tratamiento de la madre durante el parto + costo de la consejería posparto + costo de la prueba confirmatoria por western blot [WB] + costo de la RCP) $/ 1$

Costo $3=$ (costo de la consejería preparto + costo del ELISA + costo de la consejería posparto + costo del WB + costo de la RCP + costo del tratamiento del recién nacido positivo) / 0

Costo 4 = (costo de la consejería preparto + costo del ELISA + costo de la consejería posparto + costo del WB + costo de la RCP) / 1

Costo $5=$ (costo de la consejería preparto + costo del ELISA + costo del tratamiento + costo del WB + costo de la RCP) $/ 1$

Costo $6=($ costo de la consejería preparto + costo del ELISA + costo del WB + costo de la RCP $) / 1$

Costo 7 = (costo del ELISA + costo del tratamiento de la madre durante el parto + costo de la consejería posparto + costo del WB + costo de la RCP + costo del tratamiento del recién nacido positivo) $/ 0$

Costo 8 = (costo del ELISA + costo del tratamiento de la madre durante el parto + costo de la consejería posparto + costo del WB + costo de la RCP) / 0

Costo $9=$ (costo del ELISA + costo de la consejería posparto + costo del WB + costo de la RCP + costo del tratamiento del recién nacido positivo $/ 0$

Costo $10=$ (costo del ELISA + costo de la consejería posparto + costo del WB + costo de la RCP) $/ 1$

a Para la construcción del árbol se utilizaron los códigos de las variables de probabilidad definidos en el cuadro 1 y los códigos de las variables de costos definidos en el cuadro 2. Los divisores representados como cero y uno al final del árbol, se refieren a los valores probabilísticos del peor desenlace posible, que es ser VIH positivo (0), y del mejor desenlace posible, que es ser VIH negativo (1).

que el número de mujeres infectadas que dieron a luz ese año fue aproximadamente de 3 600. Mediante la estrategia voluntaria - vigente en Colombia en la actualidad - solo alrededor de $30 \%$ de las mujeres embarazadas recibirían la oferta de tamizaje y se someterían a la prueba, por lo que cerca de
2700 embarazadas seropositivas al VIH no sabrían que padecen la infección y habría una gran probabilidad de que nacieran al menos 720 bebés infectados por ese virus, de los que tampoco se sabría su estado de seropositivos.

Con la estrategia universal, al optimizar el ofrecimiento de la prueba y mejorar su tasa de aceptación, la cifra de mujeres embarazadas seropositivas sin diagnóstico conocido se reduciría a una cifra cercana a 200 y la posibilidad de recién nacidos positivos disminuiría a cerca de 52 . Según estos estimados, el número de recién nacidos de madres seropositivas que nacerían sin 
FIGURA 2. Nodo de decisión para los valores de costo correspondientes a las tres estrategias analizadas ${ }^{a}$

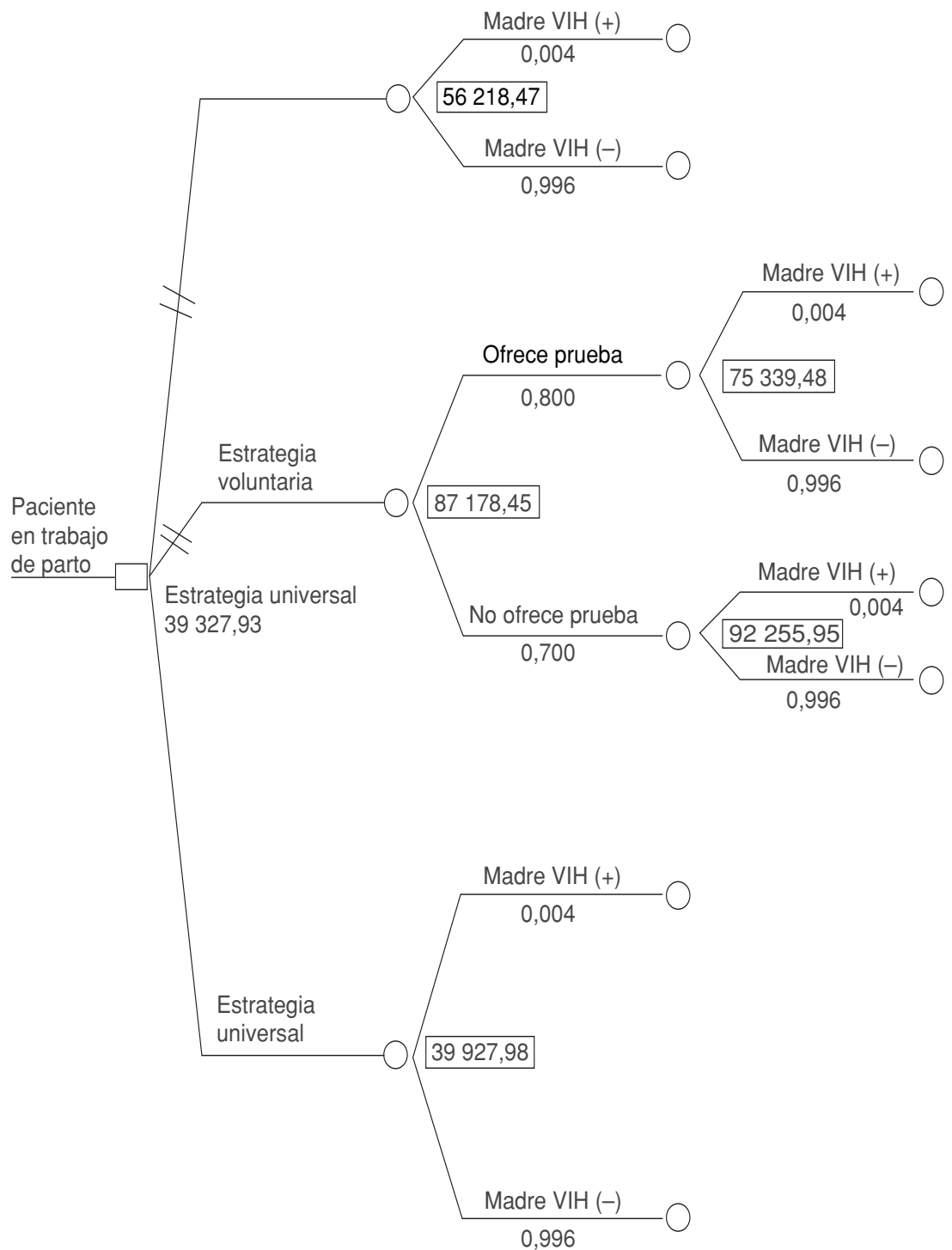

a Los códigos de las variables empleadas se definen en el cuadro 1. Los valores que aparecen debajo de las ramas corresponden a la probabilidad de ocurrencia del evento. Los valores encerrados en cuadros corresponden al costo en pesos colombianos: US $\$ 1,00=\$ 2300,00$ pesos colombianos, según la tasa establecida por el Banco de la República de Colombia para febrero de 2005 (http://www.businesscol.com/economia/dolar_2005.htm).

CUADRO 3. Ahorro aproximado de la estrategia universal con respecto a las otras estrategias analizadas

\begin{tabular}{lcccc}
\hline & & & \multicolumn{2}{c}{ Ahorro $^{\mathrm{a}}$ por cada caso adicional detectado } \\
\cline { 4 - 5 } Estrategia & Efectividad & Costo $^{\mathrm{b}}$ & Universal vs opcional & Universal vs voluntaria \\
\hline Opcional & 0,9990 & 56000,00 & -24000000 & \\
Universal & 0,9997 & 39000,00 & & -96000000 \\
Voluntaria & 0,9992 & 87000,00 & &
\end{tabular}

${ }^{a}$ El ahorro se calculó como la razón incremental del costo en función de la efectividad, según la siguiente ecuación: ahorro = (costo de la estrategia 2 - costo de la estrategia 1) / (efectividad de la estrategia 2 - efectividad de la estrategia 1).

${ }^{b}$ En pesos colombianos: US $\$ 1,00=\$ 2300,00$ pesos colombianos, según la tasa establecida por el Banco de la República de Colombia para febrero de 2005 (http://www.businesscol.com/ economia/dolar_2005.htm). la infección gracias al tratamiento profiláctico oportuno se elevaría a 668. Ambas medidas marcan una clara diferencia a favor de la estrategia de tamizaje universal.

Los resultados del análisis de sensibilidad simple de las variables contenidas en el árbol de decisión demostraron que en todos los casos se mantiene la razón marginal positiva de la relación costo-efectividad, lo que además confirma la robustez de este modelo (figura 3).

Para el análisis de sensibilidad bifactorial se emplearon variables asociadas con la efectividad de las estrategias de tamizaje, como la prevalencia de la infección por el VIH y la tasa de positivos falsos. Al variar los valores de la prevalencia de la enfermedad entre $0 \%$ y $20 \%$, la curva resultante para la estrategia universal se mantuvo con costos inferiores y efectividad superior con respecto a las otras dos estrategias. Asimismo, al variar la tasa de resultados positivos falsos en la prueba de tamizaje, la estrategia universal se mantuvo con menor costo hasta un punto de corte de $10 \%$ con relación a las estrategias voluntaria y opcional. Solamente a partir de una tasa de positivos falsos superior a $10 \%$, la estrategia de tamizaje universal pasó a ser la más costosa de las tres analizadas. Cuanto mayor es la aceptación de la prueba por parte de la embarazada, más disminuyen los costos de las estrategias universal y voluntaria.

La estrategia opcional tuvo un menor costo de tamizaje solamente si no se contemplaban los costos a mediano y largo plazos, como los relacionados con el seguimiento y el tratamiento de los casos no prevenidos, que serían enormes. Esto hace que las estrategias universal y voluntaria sean en la práctica las empleadas en casi todos los sistemas de salud.

Según los resultados del análisis bifactorial realizado con distintos valores de prevalencia de la infección por el VIH y tasas variables de resultados positivos falsos, la estrategia de tamizaje universal fue menos costosa que la voluntaria y más efectiva que las otras dos estrategias en prácticamente cualquier combinación de las mismas, 
FIGURA 3. Relación entre el costo y la efectividad de las tres estrategias analizadas

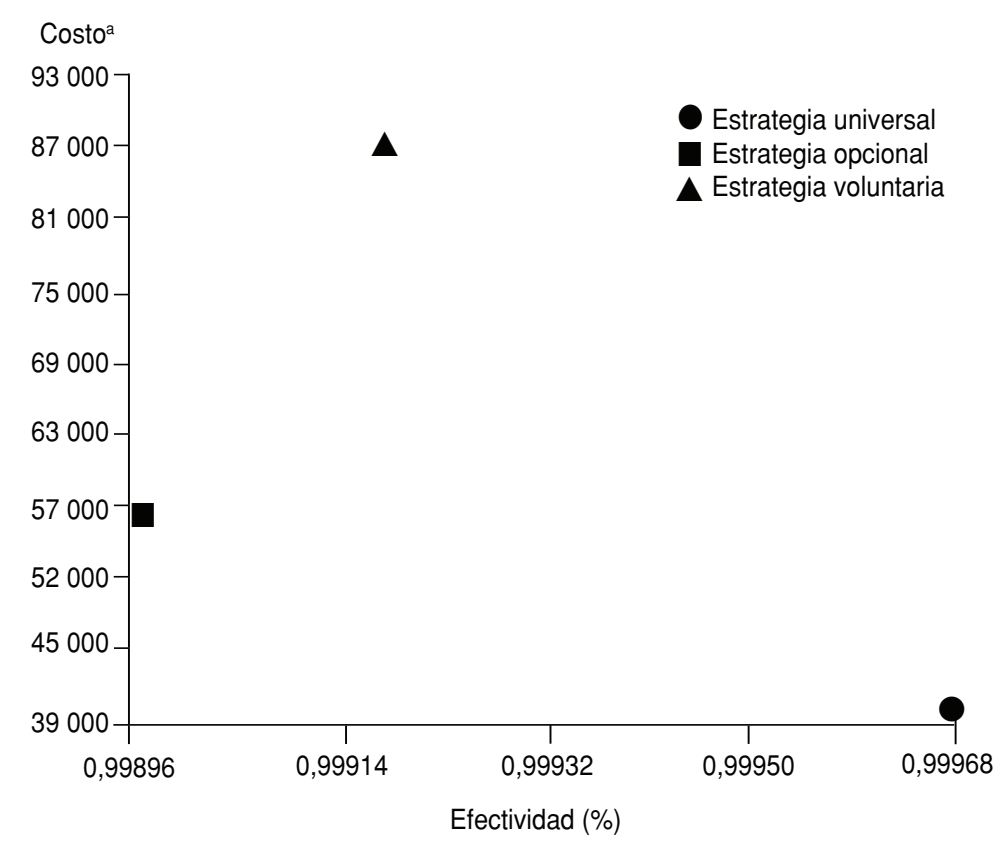

${ }^{a}$ Costo en pesos colombianos: US $\$ 1,00=\$ 2300,00$ pesos colombianos, según la tasa establecida por el Banco de la República de Colombia para febrero de 2005 (http://www.businesscol. com/economia/dolar_2005.htm).

independientemente de la tasa de aceptación materna para realizarse la prueba de tamizaje.

\section{DISCUSIÓN}

En diferentes estudios se comparan diversas estrategias de prevención de la transmisión vertical del VIH para definir la mejor alternativa aplicable a poblaciones vulnerables, como las embarazadas y los recién nacidos, según la capacidad específica de determinados sistemas de salud $(7,8,17,18,20)$. Se han evaluado poblaciones con prevalencias altas (mayores de 10\%) y bajas (menores de $1 \%)(21,22)$. Independientemente de los costos específicos que el sistema de salud esté dispuesto a asumir, la estrategia de tamizaje universal presenta ventajas sobre el tamizaje voluntario, por lo que los Centros para el Control y la Prevención de Enfermedades (CDC) de los Estados Unidos de América han recomendado su adopción como estrategia nacional en ese país $(20,21)$. Entre otros argumentos, se considera que la oferta de la prueba de tamizaje de la infección por el VIH como parte de los análisis de laboratorio que se realizan habitualmente a las mujeres embarazadas, pero dejando abierta la posibilidad de rechazarla, puede aumentar la tasa de aceptación de esa prueba $(18,19)$.

De acuerdo con los resultados obtenidos en el presente estudio, la estrategia de tamizaje universal para la detección de la infección por el VIH en mujeres embarazadas que asisten para el parto a centros de salud del primer, segundo o tercer nivel de atención de Colombia, como parte del Plan Obligatorio de Salud, es una alternativa más efectiva en función del costo que las estrategias voluntaria y opcional. La estrategia universal permite detectar más casos de mujeres embarazadas seropositivas al VIH y, por tanto, aumenta las posibilidades de realizar tratamientos profilácticos y reducir el número de niños que nacen con esta grave infección. Si se toman en cuenta los costos de la atención de los recién nacidos seropositivos durante su primer año de vida, el tamizaje universal supera a las otras dos estrategias analizadas. Tanto la relación costoefectividad como el ahorro que representa la estrategia universal con respecto a las otras dos, respaldan esta afirmación. El modelo planteado es robusto y la relación costo-efectividad de la estrategia de tamizaje universal se mantiene como la mejor, independientemente de posibles fluctuaciones en las variables involucradas directamente en los cálculos, como la prevalencia o la sensibilidad de las pruebas diagnósticas.

La estrategia de tamizaje universal mantuvo la mejor relación costoefectividad con valores de prevalencia de infección por el VIH relativamente bajos, como los informados en Colombia.

La estrategia de tamizaje universal reflejó un considerable ahorro por cada embarazada positiva adicional detectada con relación a las otras dos estrategias, ya que permitió aplicar tratamientos profilácticos durante el parto y evitar el nacimiento de niños infectados. En el modelo empleado se tomaron en consideración los costos del tratamiento durante el primer año de vida de los recién nacidos infectados, pero no los asociados con la atención de las madres después del parto y con las complicaciones de la enfermedad. Tampoco se tomaron en cuenta los costos sociales y las pérdidas por el ausentismo laboral asociados con el cuidado de estos niños, lo que habría incrementado notablemente el ahorro a favor de la estrategia de tamizaje universal.

Los resultados positivos falsos y las variaciones en los valores predictivos positivos de las pruebas de tamizaje generan costos y riesgos adicionales para el sistema de salud, aunque el empleo de pruebas de tamizaje de tercera generación (de mayor especificidad) los reduce a menos de $0,3 \%$. Además, el número de resultados positivos falsos y las variaciones en los valores predictivos positivos disminuyen considerablemente al bajar la prevalencia, por lo que se recomienda emplear pruebas de tercera generación de alta sensibilidad en el tamizaje universal de la infección por el VIH en las mujeres embarazadas. 
En cuanto a las consideraciones éticas, la estrategia de tamizaje universal permite proteger el derecho de los recién nacidos a recibir atención médica ante una enfermedad crónica, incapacitante, estigmatizadora y mortal, para la que no se cuenta con tratamiento eficaz en la actualidad y que representa una alta carga económica y social para los sistemas nacionales de salud. Esta estrategia permite a las madres ejercer su derecho a no someterse a la prueba, mediante su declaración y firma en la historia clínica. También se protege la salud de los profesionales involucrados en la atención del parto, ya que el conocimiento del estatus positivo de la madre puede ayudar a reducir el riesgo laboral adicional que representa el contacto físico con sangre infectada.

El análisis presentado se realizó desde el punto de vista del pagador de los servicios, es decir, del Sistema General de Seguridad en Salud de Colombia. Se puede pensar que para tomar una decisión política adecuada sobre el mejor sistema de tamizaje de

1. Programa Conjunto de las Naciones Unidas sobre el VIH/SIDA. Asesoramiento y pruebas voluntarias del VIH para mujeres embarazadas en países con una alta prevalencia del VIH: elementos y cuestiones. Ginebra: ONUSIDA; 2000.

2. Programa Conjunto de las Naciones Unidas sobre el VIH/SIDA, Organización Mundial de la Salud. Situación de la epidemia de SIDA, diciembre de 2005. Ginebra: ONUSIDA, OMS; 2005. Hallado en http://www.unaids.org/ epi/2005/doc/EPIupdate2005_pdf_sp/Epi_ 01_sp.pdf. Acceso el 30 de mayo de 2008.

3. Instituto Nacional de Salud de Colombia. Veinte años de VIH en Colombia. Bol Inst Nac Salud. 2004;3:45-60.

4. Programa Conjunto de las Naciones Unidas sobre el VIH/SIDA. Iniciativa Nacional para la Reducción de la Transmisión Vertical del VIH en Colombia. Santa Fe de Bogotá: ONUSIDA; 2005. Hallado en: http://www. onuSIDA.org.co/otrosproyectos/rtmh/ resumen.htm. Acceso el 30 de mayo de 2008.

5. Organización Internacional para las Migraciones. Programa de VIH/SIDA. Santa Fe de Bogotá: OIM-Colombia; 2004. Hallado en: http:/ / www.oim.org.co/modulos / contenido $/$ default.asp?idmodulo=55. Acceso el 22 de agosto de 2008.

6. Fondo de las Naciones Unidas para la Reducción del VIH/SIDA, REDSALUD. Iniciativa nacional para reducir la transmisión maternoinfantil del VIH/SIDA. Ámbito Médico la infección por el VIH es necesario rehacer el análisis desde el punto de vista de la sociedad, tomando en cuenta, además, los costos relacionados con la atención de las madres después del parto y las secuelas de la enfermedad, así como los costos económicos y sociales por la muerte, el ausentismo laboral, la afectación de la familia, etc. No obstante, los resultados obtenidos a partir de los costos directos demuestran inequívocamente que la estrategia de tamizaje universal representa un enorme ahorro de recursos por cada embarazada infectada que se detecta. La incorporación de los costos indirectos y sociales debe aumentar ese ahorro y confirmar que la estrategia de tamizaje universal para la infección por el VIH es la mejor alternativa para Colombia.

Si se logra capacitar a los profesionales de la salud para que ofrezcan la prueba de tamizaje a todas las embarazadas, la estrategia de tamizaje voluntario podría tener una relación costoefectividad muy similar a la de la estrategia de tamizaje universal. No

\section{REFERENCIAS}

(Colombia). 2004;6(67). Hallado en: http:// www.medilegis.com/BancoConocimiento/A/ AM67_AP_VIH/AM67_AP_VIH.asp. Acceso el 22 de agosto de 2008.

7. U.S. Preventive Services Task Force. Screening for human immunodeficiency virus. Guide to clinical preventive services. 2nd ed. Washington, D.C.: U.S. Department of Health and Human Services; 1996.

8. Stoto MA, Almario DA, McCormick MC. Reducing the odds: preventing perinatal transmission of HIV in the United Status. Washington, D.C.: National Academy Press: 1999; 2:80-1.

9. Connor EM, Sperling RS, Gelber R, Kiselev P, Scott G, O'Sullivan MJ, et al. Reduction of maternal-infant transmission of human immunodeficiency virus type 1 with zidovudine treatment. Pediatric AIDS Clinical Trials Group Protocol 076 Study Group. N Engl J Med. 1994;331:1173-80.

10. Centers for Disease Control and Prevention. Rapid HIV antibody testing during labor and delivery for women of unknown HIV status. A practical guide and model protocol. Atlanta, Georgia: CDC. Hallado en: http://www.cdc. gov/hiv/topics/testing/resources/fact sheets/rt_women.htm. Acceso 30 de mayo de 2008.

11. República de Colombia, Ministerio de Salud. Decreto 1543 de 17 de junio de 1997 por el cual se reglamenta el manejo de la infección por el virus de inmunodeficiencia humana obstante, en sistemas de salud como el colombiano, en el que no es totalmente factible realizar una consejería óptima por diversos factores - como el poco tiempo disponible para la consulta, la gran carga laboral de los profesionales de la salud y el bajo nivel educacional de una gran parte de las embarazadas que asisten a los hospitales-, la estrategia universal sería la de mayor utilidad y permitiría salvar vidas.

Los resultados obtenidos en el presente trabajo demuestran claramente las ventajas de la estrategia de tamizaje universal, que se utiliza actualmente en Colombia, es más costosa a mediano y largo plazos que la universal y tiene menor efectividad y capacidad de prevención. Se recomienda a las autoridades nacionales de salud realizar el tamizaje de todas las embarazadas colombianas con pruebas de tercera generación de detección de la infección por el VIH. Este cambio permitiría optimizar los recursos disponibles y reducir la mortalidad sin vulnerar los derechos fundamentales de ninguno de los actores del sistema.
(VIH), síndrome de la inmunodeficiencia adquirida (SIDA) y las otras enfermedades de transmisión sexual. Santa Fe de Bogotá: Ministerio de Salud; 1997. Hallado en: http:// www.presidencia.gov.co/prensa_new / decretoslinea/1997/junio/12/dec1543121997. pdf. Acceso el 6 de marzo de 2008.

12. Bulterys $M$, Nolan ML, Jamieson DJ, Domínguez K, Fowler MG. Advances in the prevention of mother-to-child HIV-1 transmission: current issues, future challenges. AID Scie. 2004;2(4):123-30.

13. Romero SL. Sondeo sobre la aplicación de la prueba para VIH/SIDA en profesionales asistentes al I Congreso Costeño de GinecoObstetricia. Santa Marta, Colombia 2001. Barranquilla: Centro de Asesoría y Consultoría; 2001.

14. Romero SL. Sondeo sobre la aplicación de la prueba para VIH/SIDA en profesionales asistentes al XXIII Congreso Nacional de GinecoObstetricia. Cartagena, Colombia 2002. Barranquilla: Centro de Asesoría y Consultoría; 2002.

15. Nakchabandi I, Longenecker JC, Ricksecker MA, Latta RA, Healton C, Smith DG. A decision analysis of mandatory compared with voluntary HIV testing in pregnant women. Ann Intern Med. 1998;128(9):760-7.

16. U.S. Preventive Service Task Force. HIV testing among pregnant women, United States and Canada, 1998-2001. MMWR. 2002;51:1013-6.

17. U.S. Preventive Services Task Force. Screening for human immunodeficiency virus. 
Guide to clinical preventive services. 2nd ed. Washington, D.C.: U.S. Department of Health and Human Services; 1996.

18. Centers for Disease Control and Prevention. Rapid HIV antibody testing during labor and delivery for women of unknown HIV status. A practical guide and model protocol. Atlanta, Georgia: CDC; 2004. Hallado en: http://www.cdc.gov/hiv/topics/testing/ resources/guidelines/rt-labor\&delivery.htm. Acceso el 22 de agosto de 2006.

19. República de Colombia, Ministerio de la Protección Social. Acuerdo 282 de diciembre 22 de 2004. Por el cual se fija el valor de la unidad de pago por capitación del Plan Obligatorio de Salud de los Regímenes Contributivo y Subsidiado para el año 2005 y se dictan otras disposiciones. Santa Fe de Bogotá: Ministerio de la Protección Social; 2004.
Hallado en: http://www.minproteccion social.gov.co/pars/cajaherram/documen tos/Biblioteca/CompendioNormativo/acuer do 282.pdf. Acceso el 1 julio de 2006.

20. República de Colombia, Congreso de la República. Proyecto de Reforma Ley 100 por el cual se realizan modificaciones al Sistema General de Seguridad Social en Salud (SGSSS) y se dictan otras disposiciones respecto al fortalecimiento del ejercicio de las profesiones de la salud. Santa Fe de Bogotá: Congreso de la República; 2004. Hallado en: http://www. dasaludputumayo.gov.co/ProyectoL18004.pdf. Acceso el 22 de agosto de 2008.

21. Ministerio de la Protección Social, Fundación para la Investigación y el Desarrollo de la Salud y la Seguridad Social. Guía nacional para el manejo de VIH/SIDA en Colombia basada en la evidencia. Santa Fe de Bogotá: Ministerio de la Protección Social, FEDESALUD; 2004. Hallado en http://www.medicolegal.com.co/ $\mathrm{rml} /$ files/noticias/vih_resolu_3442_06.pdf. Acceso 22 de agosto de 2008.

22. Leviton L. Evaluation use: advances, challenges and applications. Am J Eval. 2003; 24(4):525-35.

23. TreeAge Health Products. Using TreeAge Pro healthcare module. Williamston, Maryland: TreeAge Health Products; 2008. Hallado en http://www.treeage.com/products/healthD etails.html. Acceso el 26 de febrero de 2007.

Manuscrito recibido el 21 de julio de 2006. Aceptado para publicación, tras revisión, el 23 de enero de 2008.

ABSTRACT Objectives. To apply decision analysis to compare the cost-effectiveness of three strategies for HIV screening of pregnant women and to recommend the one most appropriate for the health care system of Colombia.

A comparison of three screening strategies for prevention of perinatal HIV infection in Colombia: a decision analysis model
Methods. An economic study applying decision analysis to three types of HIV screening of expectant women: voluntary, universal, and optional. All the women in Colombia with unknown HIV status who were admitted for child birth were included. The study included all the direct medical costs incurred from the time of testing through the first year following delivery, according to the General System for Healthcare Social Security. Cost-effectiveness ratio and the savings of each of the strategies were compared.

Results. For every 10000 women, the universal strategy detected five cases more than the voluntary strategy and seven cases more than the optional. The universal strategy carried a cost of approximately US\$ 17 for each HIV-positive newborn; that is, less than half of that of the voluntary strategy (US\$ 38) and less than the optional (US\$ 24). According to the bifactorial analysis, the universal screening strategy was less costly than the voluntary and more effective than both of the others, regardless of prevalence, the false-positive rate of each method, and the rate of maternal compliance with screening.

Conclusions. The screening strategy currently in use in Colombia is more costly (in both the medium- and long-term), less effective, and less capable of prevention, than the universal screening strategy. The recommendation to the national health authorities of Colombia is to begin screening all pregnant women for HIV infection using third-generation testing.

Key words Disease transmission, vertical; HIV; mass screening; perinatal care; costs and cost analysis; Colombia.

\section{ERRATUM \\ Salomao $R$ et al. Device-associated infection rates in intensive care units of Brazilian hospitals: findings of the International Nosocomial Infection Control Consortium, Rev Panam Salud Publica 2008;24(3):195-202}

The third author's last name was spelled incorrectly in the above-mentioned article.

Incorrect: Grimberg Correct: Grinberg 